\title{
Evaluation of pipe-jacking forces based on direct shear testing of reconstituted
}

\section{tunneling rock spoils}

C S Choo ${ }^{1}$; D E L Ong ${ }^{2}$

Abstract: The installation of underground trunk sewer lines in the Tuang Formation of Kuching City, Malaysia utilized trenchless technology in the form of the pipe-jacking method. The evaluation of pipe-jacking forces mainly involves empirical models developed for soils, with rather limited considerations for drives through weathered rock. Therefore, a novel approach is proposed to evaluate strength parameters by reconstituting and subsequently shearing scalped tunneling rock spoils in the direct shear apparatus. The direct shear results are then applied to a well-established pipe-jacking force model, which considers arching theory. The outcomes indicate that the back-analyzed frictional coefficients, $\mu_{\text {avg }}$ are not only reliable but also related to their surrounding geologies due to soil-structure interaction. This study also highlights the significance of lubrication and effect of rock arching in assessing jacking forces. The successful characterization of reconstituted tunneling rock spoils in this paper has shown potential use in assessing jacking forces during micro-tunneling works.

Keywords: Pipe-jacking; Trenchless technology; Friction; Shear strength; Direct shear; Rocks; Arching effect; Power law; Non-linear

${ }^{1}$ Associate Lecturer, Research Centre for Sustainable Technologies, Faculty of Engineering, Science \& Computing, Swinburne University of Technology Sarawak Campus, 93350 Kuching, Sarawak, Malaysia. E-mail: cschoo@swinburne.edu.my

${ }^{2}$ Director (Acting), Research Centre for Sustainable Technologies, Faculty of Engineering, Science \& Computing, Swinburne University of Technology Sarawak Campus, 93350 Kuching, Sarawak, Malaysia. E-mail: elong@swinburne.edu.my 
Pipe-jacking may have become the preferred delivery method over conventional open trenching for installation of buried infrastructure, largely due to the mitigated disturbances to ground surface, as well as the reduced disruptions to road traffic. Such trenchless technology methods involving micro-tunneling can be implemented in the form of pipe-jacking. Pipejacking works in the central business district of Kuching City, Malaysia were necessary as trunk sewer lines were proposed to be installed in depths up to $25 \mathrm{~m}$ from the existing ground level. The pipe-jacking works traversed the pre-upper carboniferous Tuang Formation, characterized by highly fractured and tightly folded phyllite, with highly fractured lithological units of shale, metagreywacke, and sandstone (Tan, 1993). The relatively young and weathered geological formation created challenges during extraction of rock cores in soil investigation (SI) works, particularly from the argillaceous units of shale and phyllite. The SI works revealed that majority of the recovered cores of shale and phyllite had a Rock Quality Designation (RQD) value of zero. RQD is defined as the total length of recovered cores longer than $100 \mathrm{~mm}$ expressed as a percentage of the total rock core length (Deere, 1989). The low RQD values implied a lack of suitable core lengths for uniaxial compression strength (UCS) and point load testing. This made it difficult to assess the in-situ weathered rock strength parameters as the preferred in-situ pressuremeter tests were not readily available at that point in time. Furthermore, local expertise in the industry in performing the in-situ pressuremeter tests was very limited. Unfortunately, pressuremeter tests were not originally budgeted for in the investigation stage of the project.

This study was motivated by the possibility of using tunneling rock spoils for the purpose of back-analyzing pipe-jacking forces during the construction of trunk sewer lines in Kuching 51 City, Malaysia (Choo and Ong, 2012). Rock spoils from tunneling works were collected from four different pipe-jacking drives. Direct shear testing of reconstituted tunneling rock spoils 
was used as an alternative method of obtaining rock strength parameters so that pipe-jacking forces could be reliably understood and back-analyzed. Results from direct shear tests were applied to a well-established empirical pipe-jacking force equation. The calculated pipejacking forces with respect to drive lengths were compared to corresponding measured values. It has been found that the back-analyzed values of $\mu$ agreed reasonably well with the suggested range of $\mu=0.1-0.3$ considering lubrication (Stein et al., 1989) and must be explained with reference to their surrounding geologies due to soil-structure interaction.

\section{DIRECT SHEAR TESTING}

The direct shear test has been used to determine shear strength properties of various soilstructure interfaces. Such applications of direct shear testing range from fundamental studies on the effects of dilatancy (Simoni and Houlsby, 2006), particle size (Yu et al., 2006) and shear box platen fixities (Jewell, 1986) to field applications including skin friction generated between various construction materials (Potyondy, 1961), geosynthetic-reinforced structures (Anubhav and Basudhar, 2013; Arulrajah et al., 2013), large-scale hydropower projects, and excavations of lunar regoliths (Iai and Luna, 2011). Direct shear tests can be conducted under conditions of constant normal load (CNL), constant normal stiffness (CNS), or constant volume (CV) (Pellet and Keshavarz, 2014). The direct shear tests in this current study were conducted under CNL conditions to reflect the in-situ stress conditions along the drives.

The direct shear test has also been used for studies on pipe-jacking forces. The effect of surface roughness for some common jacking pipe materials was studied by displacing the top half of a shear box along the outer periphery of the studied pipes (Staheli, 2006). The shear box was filled with sand and respective frictional coefficients for the respective pipe materials were produced. The frictional coefficients were subsequently applied to back- 
force model was developed from the back-analyses; however this force model was developed for unlubricated drives traversing clays and sands only.

A separate study on the effect of lubrication using a modified shear box, involves the dragging of a concrete block over a large sample of soil (Shou et al., 2010). Lubricant was placed between the concrete block and the soil. Measurements were made of the critical drag force required to move the concrete block, with variations made to the lubricant type and applied normal force on the concrete block. An unlubricated condition was used as a benchmark. The results showed that the lubricant mix of plasticizers with polymer fluid reduced the pipe-soil interface friction by $75 \%$, due to the discrete layer of plasticizer present between the concrete block and soil. The findings were subsequently applied to a case study of a $2.85 \mathrm{~m}$ diameter pipe of length $400 \mathrm{~m}$ jacked through gravel at a depth of $9.65 \mathrm{~m}$ below the ground surface. There was a large discrepancy between the back-analyzed jacking forces against those resulting from the modified direct shear test. This discrepancy was attributed to the overestimation of the pipe-soil contact area.

Therefore, in view of limited studies on pipe-jacking in relatively young, weathered sedimentary and metamorphic rocks, this paper makes a novel attempt to effectively quantify jacking forces via a systematic approach of utilizing reconstituted rock spoils tested in a direct shear apparatus.

\section{EMPIRICAL METHOD TO DETERMINE JACKING FORCES}

Some commonly used equations for predicting forces in pipe-jacking works through soil have been derived statistically (Chapman and Ichioka, 1999), empirically (Osumi, 2000), or experimentally (Staheli, 2006). Very limited considerations are made for drives in rock. In empirically derived jacking force models, two approaches are used for assessing frictional jacking forces. 
101 The first considers the soil stresses acting on the outer periphery of the pipeline. This 102 approach is typically dependent on the strength properties of the geology surrounding the

103 pipe. However, the usage of such equations is often restricted to drives traversing sands or 104 clays, with limited experience for tunneling through weathered rocks. The evaluation of 105 jacking forces through weathered rocks can be made further complicated due to the 106 surrounding highly fractured rock mass or, in contrast, the presence of an arching effect.

107 Pellet-Beaucour and Kastner (2002) developed a jacking force equation, which 108 incorporated the geomechanical phenomenon of soil arching. Terzaghi (1936) observed this 109 phenomenon through the introduction of a trap door beneath a sand mass. Opening the trap 110 door disturbed the geostatic stresses, thus inducing a relaxation of soil stresses above the trap 111 door. Such phenomenon is also evident in rock tunnels. Hence, the model developed by 112 Pellet-Beaucour and Kastner (2002) was chosen for use in this paper due to its inclusion of 113 the soil arching effect. This jacking force model is shown in Eq. (1), which is expressed as

114 the vertical soil stress at the pipe crown, $\sigma_{E V}$ shown in Eq. (2).

$$
F=\mu L D_{e} \frac{\pi}{2}\left[\left(\sigma_{E V}+\frac{\gamma D_{e}}{2}\right)+K_{2}\left(\sigma_{E V}+\frac{\gamma D_{e}}{2}\right)\right]
$$

$\sigma_{E V}=\frac{b\left(\gamma-\frac{2 C}{b}\right)}{2 K \tan \varphi}\left(1-e^{-2 K \frac{h}{b} \tan \varphi}\right)$

117 where $F=$ total frictional jacking force; $L=$ pipe span; $D_{e}=$ outer pipe diameter; $\gamma=$ soil unit

118 weight; $h=$ soil cover from the ground level to the pipe crown; $K=$ lateral earth pressure 119 coefficient; $K_{2}=$ thrust coefficient of soil acting on the pipe, with a suggested value of 0.3 120 (French Society for Trenchless Technology, 2006); $C=$ soil cohesion; and $\phi=$ soil internal 121 friction angle. $\mathrm{C}$ and $\phi$ are derived from the in-situ rock mass above the pipe, where arching 122 would develop. $b$ is the influencing soil width above the pipe and is expressed in Eq. (3) as 
$123 b=D_{e}\left(1+2 \tan \left(\frac{\pi}{4}-\frac{\varphi}{2}\right)\right)$

124 The formulation of $\sigma_{E V}$ is based on the classic limit equilibrium approach developed by 125 Terzaghi (1943), which was dependent on the Mohr-Coulomb (MC) strength parameters of 126 the yielding soil.

127 During pipe-jacking works, tunnel boring creates changes to the geostatic stresses, 128 resulting in soil relaxation around the tunnel and pipe. This phenomenon redistributes soil 129 stresses around the bored tunnel, allowing the tunnel to self-stand through the phenomenon of 130 arching. The result is a reduction of vertical stresses experienced at the pipe crown, $\sigma_{E V}$.

$131 \mu$ is the coefficient of pipe-soil friction, given in Eq. (4) as

$\mu=\tan \delta$

133 where $\delta=$ pipe-soil friction angle.

134 For Eq. (1), values of $\mu$ between $0.1-0.3$ were recommended for lubricated drives or 135 'fluid friction' (Stein et al., 1989). These values for lubricated drives were previously used 136 for the prediction of jacking forces during tunneling in sands and clays (French Society for

137 Trenchless Technology, 2006; Pellet-Beaucour and Kastner, 2002), as well as limestone 138 (Barla et al., 2006). Pellet-Beaucour and Kastner (2002) reported $\mu$ values below 0.1, which 139 also indicated adequate lubrication. The recommended frictional coefficients for lubricated 140 drives assume ideal lubricating conditions, whereby a distinct lubricating layer is formed 141 between the jacked pipeline and the surrounding geology.

142 The use of these jacking force models is still dependent on the surrounding rock strength 143 characteristics and pipe-rock interface properties, which are difficult to assess in this Kuching 144 City study due to the friability of the extracted rock cores from the Tuang Formation. A novel 145 approach of acquiring the representative rock strength properties from reconstituted tunneling rock spoils for the assessment of jacking forces is thus studied hereinafter. 


\section{PROPOSED METHOD OF TESTING RECONSTITUTING ROCK SPOILS}

148 Rock cores obtained from the SI works at the launching and retrieving shaft locations

149 along the Tuang Formation in Kuching City revealed very low RQD values. The average

150 RQD value was $17 \%$ for rock cores obtained from the studied drives. In total, $30.7 \mathrm{~m}$ of core

151 lengths were extracted, of which 13.4 m produced RQD values of zero. A majority of these

152 extracted cores were highly fractured and not fully intact.

153 Similar observations were made by Ong and Choo (2011) for a separate project sited also

154 in the Tuang Formation. In this case study, 206 m of rock cores were extracted, of which 151

$155 \mathrm{~m}$ had RQD values of zero. This provided challenges in conducting UCS tests and

156 consequently difficulties in obtaining useful, consistent strength values.

157 In other microtunneling projects, it may have been possible to survey the rock faces

158 exposed in more detail during shaft construction (Barla et al., 2006). In this study,

159 unfortunately exposed rock faces were quickly shotcreted as stand-up time was critical to

160 prevent water ingress, which would have resulted in ground surface deformations. Therefore,

161 joint directions of the rocks could not be further studied.

162 Furthermore, tests for determining strength anisotropy (e.g. UCS, Brazilian tensile test,

163 triaxial test, point load test, shear wave velocity) are usually conducted on intact cylindrical

164 cores (Bhasin et al., 1995; Desai and Salami, 1987; Gurocak et al., 2012; Saroglou et al., 165 2004; Shea Jr and Kronenberg, 1993; Yilmaz, 2009) or prismatic specimens (Ramamurthy et 166 al., 1993; Singh et al., 2002; Tiwari and Rao, 2007). As a result of the challenges in obtaining 167 natural intact rock cores of suitable lengths, and also due to the friability of the in-situ rock, it 168 was not practically possible to ascertain the anisotropy of the rock mass.

169 Thus, a novel method to test and assess the reconstituted micro-tunneling rock spoils was 170 initially developed for a typical pipe-jacking drive in Kuching, Malaysia (Choo and Ong,

171 2012). Literature review shows that the reconstitution of rock fragments has been 
172 successfully conducted on Australian black coal in order to homogenize the high variability

173 of its mechanical properties (Jasinge et al., 2009). Cement was used to stabilize the coal

174 samples. UCS and PLT tests were conducted on the reconstituted stabilized coal. The testing

175 results indicated reasonable homogeneity of the strength of the reconstituted coal. This

176 particular study successfully showed good potential in obtaining useful strength parameters

177 and correlations for reconstituted rock samples. This fundamental understanding was applied

178 hereinafter to allow for direct shear testing of tunneling rock spoils to obtain the relevant

179 shear strength properties.

180 In the current study, as the in-situ rock mass is naturally friable due to deep weathering in

181 a hot and humid climate (Malaysia is located on the Equator) (Tan, 1993), the concept of

182 reconstituting the excavated spoils into a shear box is to 're-create' the situation of intensely

183 fractured, irregular and poorly sorted rocks with many arbitrary joints or fine cracks found on

184 the surfaces of the in-situ samples. This could be described as a highly weathered 'soft rock'

185 which perhaps behaves more closely to soil, and hence the possible use of 'soil' equations as

186 shown in Eqs. (1) and (2). If proven reliable, research into the properties of reconstituted

187 tunneling rock spoils could provide a platform for consistent prediction of jacking forces

188 accrued during pipe-jacking works in highly fractured geology.

189 Characteristics of test samples

190 Petrographic analyses of thin sections were conducted on rock cores obtained from pipe-

191 jacking shaft locations. Fine-grained sandstone (metagreywacke) (see Fig. S1(a)) was

192 composed mainly of angular to subangular quartz grains. X-ray diffraction (XRD) tests

193 conducted on the samples of sandstone further validated the presence of quartz. Grains of

194 shale were mainly composed of clay minerals and silt-sized quartz grains, with tiny flakes of

195 mica (see Fig. S1(b)). Metamorphic phyllite was mainly composed of fine-grained quartz

196 with flaky sericite and mica (see Fig. S1(c)). The grains in phyllite were finer than those 
197 found in shale. XRD tests did not reveal the presence of bentonite slurry, if any. (Note that 198 petrographic images can be found in Fig. S1 in the Supplemental Data.)

199 Test samples of tunneling rock spoils were obtained from desanding machines or 200 decantation chambers at four pipe-jacking sites in Kuching, Malaysia. Samples were 201 collected from the decantation chambers, which removed coarse particles from the tunneling

202 rock spoils transported from underground up to the ground surface by a slurry system. The 203 decantation chambers used standard screens mounted on shaker decks to segregate coarser spoils from the transport slurry thus allowing for reuse of the slurry fluid for continued transportation of tunneling rock spoils.

The particle size distribution tests of the tunneling rock spoils were conducted according to testing standard ASTM D422-63 (2002). The particle size distribution curves for the tunneling rock spoils before and after scalping are presented in Fig. 1. Scalping was conducted to fulfil direct shear test requirements. Based on sieve analysis, both sets of spoils (before and after scalping) comprised of sand-sized grains and can be classified as poorly

211 graded tunneling rock spoils according to both the Unified Soil Classification System (ASTM, 212 2000) and the Australian Soil Classification System (Standards Australia, 1993). Table 1 shows the results of sieve analyses performed on the scalped spoils.

\section{EXPERIMENTAL PROCEDURE}

215 Strain-controlled drained direct shear tests were conducted on the tunneling rock spoils in accordance to ASTM D 3080 (2003) and AS 1289.6.2.2 (1998), through the use of the

217 GeoComp ShearTrac II apparatus. The fully automated direct shear system allows for full 218 automation of testing and extraction of test results, ensuring reliability of the tests. Control of 219 the testing parameters (consolidation, normal pressure, shear strain rate, and limits) was 220 achieved through pre-set limits of the automation functions, allowing for close scrutiny of shear stresses and vertical displacements with horizontal deformation. The direct shear tests 
were conducted under constant normal load (CNL) conditions to reflect the in-situ stress conditions along the drives.

Scalping of the spoils was carried out in relation to the size of the shear box, where the maximum particle size in the tested samples did not exceed 1/10th of the thickness of the test specimen (Head, 1992). Successfully scalped samples were compacted in three layers within the shear box by using a tamping plate to ensure even distribution of the compaction effort. Test samples achieved relative densities ranging from $65 \%$ to $99 \%$ (see Table 1). Initial tests were conducted at effective normal stresses representative of the in-situ overburden pressures of the pipe-jacking works. Additional tests were performed beyond the confining pressures in order to generate more data points to establish failure criteria. The said effective normal stresses experienced by each sample type are also presented in Table 1. Specimens were saturated and consolidated under the applied effective normal stresses until the completion of primary consolidation, which was typically achieved within 5 minutes. ASTM (2003) recommends for clean dense sands to be sheared at a rate computed from Eq. (6).

$d_{r}=d_{f} / t_{f}$

where $d_{f}=$ estimated horizontal displacement rate at failure $(5 \mathrm{~mm}) ; t_{f}=$ total estimate elapsed time to failure (600 sec for clean dense sands); and $d_{r}=$ displacement rate $(\mathrm{mm} / \mathrm{sec})$. Based on the recommended values for $d_{f}$ and $t_{f}$, the shearing rate, $d_{r}$ was $0.0083 \mathrm{~mm} / \mathrm{sec}$. A lower shearing rate of $0.0017 \mathrm{~mm} / \mathrm{sec}$ was adopted for dissipation of excess pore pressures, if any. The samples were all tested to a maximum applied horizontal deformation of $15 \mathrm{~mm}$, which was sufficient to achieve residual state for the samples tested.

\section{DIRECT SHEAR TEST RESULTS}

The variations of shear stress and vertical displacements against horizontal displacement from direct shear testing on scalped tunneling rock spoils are shown in Fig. 2(a). Test 1 showed distinct peak shear stress values for sandstone, before decreasing to a lower residual 
247 shear stress value. For Tests $2,3 \& 4$ on rock spoils of an argillaceous nature, the degree of 248 post-peak strain-softening was not as noticeable as tests conducted on rock spoils of an 249 arenaceous nature, i.e. sandstone. This was especially apparent on spoils of sedimentary shale. 250 Relatively large displacements were necessary to reach residual shear stresses, which is 251 typical of argillaceous materials. This was attributed to the larger grain sizes found in the 252 argillaceous spoils (Cerato and Lutenegger, 2006).

253 For vertical deformation (see Fig. 2(b)), positive values indicated compression of the test 254 specimen, while negative values indicated dilation. All tested samples showed initial 255 contractive behavior during initial increase of shear strain, indicating particulate interlocking. 256 In general, dilative behavior was observed upon reaching peak shear stresses. In Tests 2,3 \& 257 4, subsequent contraction was observed at relatively larger horizontal displacements in excess of $8 \mathrm{~mm}$, with larger applied effective normal stresses resulting in larger contractions. Particle breakage appears to have occurred at this stage. This has been attributed to the flaky and angular particles of shale spoils and phyllite spoils.

261 Non-linear strength envelopes for arenaceous (i.e. sandstone) and argillaceous (i.e. phyllite 262 and shale) rock spoils respectively are presented in Fig. 2(c). MC strength criteria were initially developed based on regressive lines through the data points obtained from direct shear testing. This was utilized to illustrate the shear strengths of the tested tunneling rock spoils. However, the suitability of linear lines of best fit was dependent on the range of stresses at which the specimens are tested. If not selected accurately, this may result in over-

267 estimation of shear strengths at extremely low or high stresses, while under-estimating shear strengths at intermediate stress levels. Therefore, power law functions were considered. Power law functions for geomaterials have been studied for various geotechnical applications

270 (Anyaegbunam, 2015; Lade, 2010; Soon and Drescher, 2007). De Mello (1977) introduced a 271 simplified power-type function stated as 
273 where $A$ and $B$ are constants. This function was adopted by Charles and Watts (1980) and De 274 Mello (1977) in characterizing the non-linear shear strength behavior of rockfills. Table 2 275 lists the values of $A$ and $B$ based on test data from the tunneling rock spoils, using Eq. (7). 276 Values of $B$ were typically between 0.6 and 1.0, which conform to power law exponent 277 values reported by Anyaegbunam (2015), i.e. $0<B<1$. For Test 2, a linear line of best fit was sufficient to represent the data points. For convenience, the linear envelope was directly characterized with a suitable MC criterion.

280 Despite the non-linearity of shear strength for the tested tunneling rock spoils, the jacking 281 force predictive model (Eqs. (1) \& (2)) is dependent on the linear MC failure criteria, and requires the use of values for $c$ ' \& $\phi$ '. Yang and Yin (2004) introduced a 'generalized tangential" technique to approximate the non-linear power law failure criterion. Similar approaches have been used in other applications (Collins et al., 1988; Drescher and Christopoulos, 1988; Soon and Drescher, 2007). The non-linearity is simplified as linear MC failure criterion tangential to the non-linear power law functions. Tangents to the respective power-type curves were applied at the effective confining pressures pertaining to the respective pipe-jacking depths (Fig. 2). Values for these tangential MC parameters for both peak and residual phases are presented in Table 3. (Note that the direct shear test results and interpreted strength profiles for Tests 2, 3, and 4 can be found in Fig. S2, Fig. S3, and Fig. S4 respectively in the Supplemental Data).

The tested specimens exhibited reduction in shear strength from peak to residual phases.

This was illustrated in the power function parameters by a decrease in $A$ values, and a corresponding increase in values of $B$ (implying reduced curvature of the non-linear power function). From the interpreted tangential MC parameters, drops in $c^{\prime}$ and $\phi^{\prime}$ were also observed. Generally, values of residual friction angle were lower than values corresponding 
with peak frictional angle. Tested spoils of sandstone (Test 1) showed significant loss of cohesion. Post-peak behavior of the sample suggests the formation of the shear zone, marked by strain softening and dilation of the specimen. Li and Aydin (2010) attributed this to the rotation and rolling of large particles, or larger quartz crystals (see Fig. S1(a)) as in the case of Test 1 .

In sands and gravels, friction angle $\phi$ ' values decreased with increasing values of coefficient of uniformity, $C_{u}$ for frictional MC specimens (Wang et al., 2013). As stated earlier, $B$ indicates the curvature of the power function strength envelope. For peak shear strengths, an increase in $C_{u}$ from Test 1 to Tests $3 \& 4$ saw a decrease in the curvature of the power function strength envelopes, as indicated by an increase in $B$. Hence, as $C_{u}$ increased, the variation of $\phi$ ' with effective normal stresses was less apparent. dilation. Similar observations were made for phyllite spoils (Test 3). Phyllite spoils exhibited the highest values for apparent cohesion, with only a slight decrease in cohesion from peak to residual phases. In contrast to the blocky quartz crystals found in sandstone (Test 1), angular and plate-like mica present in phyllite imply that formation of the shear zone was more likely to be achieved through particle breakage than through rotation and rolling of the particles (Lade et al., 1996).

\section{OF $\boldsymbol{\mu}_{\text {avg }}$}

Field measurements of pipe-jacking activities comprising of jacking forces, jacking speeds, and lubrication use are shown in Fig. 3 for Drive A where tunneling rock spoils were collected for direct shear testing. The interpreted geology, cumulative days elapsed, and cumulative lubricant injected have also been included for the respective drives. (Note that the 
322 field measurements of pipe-jacking activities for Drives B, C, and D can be found in Fig. S5,

323 Fig. S6, and Fig. S7 respectively in the Supplemental Data).

324 The jacking forces for the four pipe-jacking drives consisting of different geological 325 settings were studied. These jacking forces, with respect to the jacking length, were 326 characterized as gradients $(\mathrm{kN} / \mathrm{m})$, representing the average jacking forces for each drive, 327 respectively.

328 The strength parameters obtained from direct shear testing of scalped tunneling rock spoils were used for back-analyses of the average jacking forces through the use of the jacking force equations (Eqs. (1) \& (2)). For calculation of vertical normal stress acting on the pipeline due to arching, $\sigma_{E V}$ (Eq. (2)), peak strength parameters $c^{\prime}{ }_{p} \& \phi_{p}^{\prime}$ were used in place of $C \& \phi$, respectively. Arching is caused by initial vertical slippage of the overburden soil or rock mass over an excavated void during pipe-jacking. This usually occurs at low displacements of the soil or rock mass into the bored tunnel. Hence, peak values were used for estimating $\sigma_{E V}$. In some cases, the calculated $\sigma_{E V}$ resulted in negative values, which implied tensile soil stresses acting on the pipe. Terzaghi (1943) stated that beyond certain tunnel depths, the vertical stresses at a tunnel roof were equal to zero. From Eq. (2), $\sigma_{E V}$ is equal to zero provided

$338 \quad b \leq \frac{2 C}{\gamma}$

339 Further explanation on the measured jacking forces shall be described in detail hereinafter.

\section{CASE STUDIES}

341 The case studies described hereinafter will illustrate the use of direct shear test results

342 from shearing of reconstituted tunneling rock spoils, back-analyzed frictional coefficients,

343 and effect of construction activities. The measured jacking forces are shown, superimposed

344 with calculated average jacking force profiles based on theoretical upper $\mu=0.3$ and lower $\mu$ $345=0.1$ bounds due to lubrication (Stein et al., 1989), and corresponding back-analyzed $\mu_{\text {avg }}$ 
346 based on Eqs. (1) \& (2) using measured jacking forces from Fig. 3. The respective values of

$347 \mu_{\text {avg }}$ have been compared against recommended frictional coefficient values of between 0.1

348 and 0.3 for lubricated drives, or 'fluid friction' (Stein et al., 1989). Table 4 shows the

349 measured pipe-jacking activities from the studied drives, including face support pressure,

350 pipe weight, TBM weight, jacking speed, and lubricant usage. The results from the back-

351 analyses of jacking forces based on results from direct shear tests are also presented.

\section{Drive A}

Fig. 3 shows jacking forces, jacking speeds and lubrication for Drive A which traversed sandstone. The $1.43 \mathrm{~m}$ outer diameter, concrete pipeline (consisting of pre-cast, $3 \mathrm{~m}$ length concrete pipes) spanned $140 \mathrm{~m}$ at a depth of $12.5 \mathrm{~m}$. The average volume of injected lubrication was $47 \mathrm{~L} / \mathrm{m}$ (see Fig. 3), into a theoretical overcut annulus of $87 \mathrm{~L} / \mathrm{m}$ (see Table 4). This overcut region allowed for the injection of lubrication between the pipeline and the surrounding geology. Extracted sandstone cores from the receiving shaft of Drive A had majority RQD values of zero. The measured face support pressure was stable at $104 \mathrm{kN} / \mathrm{m}^{2}$.

360 Hence, the measured jacking forces could be analyzed in terms of frictional resistance, segregated from the face pressures. The jacking forces were well-represented with an average

362 line of best fit $\left(R^{2}=0.93\right)$ at $14.4 \mathrm{kN} / \mathrm{m}$ (see Fig. 3). From direct shear testing of sandstone

363 (Test 1), the MC parameters for use in Eq. (2) were $C=c^{\prime}{ }_{p}=50.8 \mathrm{kPa}$ and $\phi=\phi_{p}{ }_{p}=47.8^{\circ}$ 364 (see Fig. 2(c)). As stated previously, these values from the linear MC criterion were obtained by utilizing the "generalized tangential" technique on the non-linear power law function. The tangent to the non-linear function was applied at the effective overburden pressure with reference to the tunnel depth. This resulted in $\sigma_{E V}=-20.8 \mathrm{kN} / \mathrm{m}^{2}$, indicating a significant degree of arching over the pipe crown. However, negative values of $\sigma_{E V}$ implied tensile stresses acting normal to the outer pipe peripheral. For the back-analysis of $\mu_{\text {avg }}$ (see Eq. (1)), 
371 incurred during jacking through sandstone (Test 1), with the back-analyzed frictional 372 coefficient, $\mu_{\text {avg }}=0.31$. Jacking force profiles corresponding with the recommended upper $\mu$ $373=0.3$ and lower $\mu=0.1$ limits of $\mu$ values for lubricated drives are also shown in Fig. 4 . The

374 back-analyzed $\mu_{\text {avg }}$ of 0.31 matched with the upper limit of $\mu=0.3$, as recommended by Stein 375 et al. (1989) for lubricated drives. This indicates that Drive A in sandstone was lubricated 376 moderately, confirmed by the comparison between injected volumes of lubrication and 377 theoretical overcut (see Table 4).

\section{Drive B}

379 Fig. S5 shows the jacking activities for Drive B. Similar to Drive A, the jacked pipeline was of $1.43 \mathrm{~m}$ outer diameter. It also spanned $140 \mathrm{~m}$ at a depth of $12.5 \mathrm{~m}$. However, Drive B negotiated through shale (Test 2). The volume of injected lubricant averaged $682 \mathrm{~L} / \mathrm{m}$ (see Fig. S5) and was significantly in excess of the theoretical overcut annulus of $87 \mathrm{~L} / \mathrm{m}$ (see

Table 4). As summarized in Table 4, the extracted shale cores from the borehole done at both receiving and jacking shafts had RQD values ranging from 0 to $80 \%$, with a mean RQD of 26.0\%. From Test 2, the equivalent tangential peak MC parameters were $c^{\prime}{ }_{p}=0$ and $\phi_{p}^{\prime}=$ $41.4^{\circ}$ (see Fig. S2). Using these values with Eq. (2), the calculated $\sigma_{E V}$ was $34.1 \mathrm{kN} / \mathrm{m}^{2}$, indicating a reduced arching effect as compared to Drive A. The measured face support pressure was constant throughout the drive at $68 \mathrm{kN} / \mathrm{m}^{2}$; with the average jacking force measured at $29.0 \mathrm{kN} / \mathrm{m}\left(R^{2}=0.90\right.$; see Fig. S8 of the Supplemental Data). The back-analyzed

390 frictional coefficient, $\mu_{\text {avg }}$ was 0.20 . Fig. S8 illustrates that the back-analyzed $\mu_{\text {avg }}$ of 0.20 was

391 within the margin recommended by Stein et al. (1989) for lubricated drives, suggesting that

392 Drive B through shale was well-lubricated. 


\section{Drive C}

Fig. S6 shows jacking activities for Drive C, which spanned $120 \mathrm{~m}$ through phyllite (Test

395 3). Tan (1993) reported phyllite from the Tuang Formation as being bedded, tightly folded and highly sheared. From Table 4, it is observed that the extracted cores were characterized by average RQD values of $17.5 \%$, with $7.6 \mathrm{~m}$ of the total $15.1 \mathrm{~m}$ in extracted cores exhibiting RQD values of zero. The average volume of lubricant injected was $181 \mathrm{~L} / \mathrm{m}$ (see Fig. S6), slightly in excess of the theoretical overcut of $113 \mathrm{~L} / \mathrm{m}$ (see Table 4). From Test 3, the tangential peak MC parameters were $c^{\prime}{ }_{p}=57.8 \mathrm{kPa}$ and $\phi^{\prime}{ }_{p}=44.3^{\circ}$ at $\sigma^{\prime}=222 \mathrm{kPa}$ (see Fig. S3). Using these values with Eq. (2), the calculated $\sigma_{E V}$ was $-22.3 \mathrm{kN} / \mathrm{m}^{2}$, demonstrating that significant arching was present during pipe-jacking works at Drive C. The measured face support pressure was stable at $47 \mathrm{kN} / \mathrm{m}^{2}$. The average measured jacking force of $4.8 \mathrm{kN} / \mathrm{m}$ $\left(R^{2}=0.78\right)$ was the lowest of the jacking forces observed in this study (see Fig. S9 of the Supplemental Data), with back-analyzed $\mu_{\text {avg }}$ of 0.07 , indicating that Drive $\mathrm{C}$ in phyllite was very well-lubricated.

Drive D

Fig. S7 shows jacking forces for Drive D, a pipe-jacking drive spanning $228 \mathrm{~m}$, which navigated an initial $135 \mathrm{~m}$ section of stiff clay (SPT $\mathrm{N}$ value of 31), followed by a latter section through shale (Test 4). Extracted shale cores from the borehole done at the receiving shaft, corresponded with RQD values ranging from $10 \%$ to $23 \%$ with an average of $14 \%$ as

412 shown in Table 4. In the shale section of Drive $\mathrm{D}$, an average of $729 \mathrm{~L} / \mathrm{m}$ of lubricant was 413 injected into a theoretical overcut of $113 \mathrm{~L} / \mathrm{m}$ (see Table 4). Tunneling shale spoils were obtained from the latter section of the drive $(136 \mathrm{~m}$ to $228 \mathrm{~m}$ ) for direct shear testing (Test 4$)$.

415 The equivalent tangential peak MC parameters were $c^{\prime}{ }_{p}=29.0 \mathrm{kPa}$ and $\phi^{\prime}{ }_{p}=38.7^{\circ}$ at $\sigma^{\prime}=$ $416234 \mathrm{kPa}$ (see Fig. S4). From Eq. (2), the computed $\sigma_{E V}$ was $11.7 \mathrm{kN} / \mathrm{m}^{2}$. The average face 417 support pressure had minimal fluctuations, measured at $115 \mathrm{kN} / \mathrm{m}^{2}$. However, the measured 
418 jacking forces were highly scattered $\left(R^{2}=0.45\right)$ averaging at $81.1 \mathrm{kN} / \mathrm{m}$ (see Fig. S10 of the

419 Supplemental Data). This is believed to be due to a 19-day extended stoppage in the pipe-

420 jacking works, which occurred at the clay-shale interface (see Fig. S7). The subsequent back-

421 analyzed $\mu_{a v g}$ was 0.71 , indicating that lubrication during pipe-jacking of Drive D was

422 ineffective, despite having about 6.5 times more lubricant injected into the theoretical overcut.

423 This shall be explained in the discussion section later.

424 Summary of drives

425 Using the "generalized tangential" technique, equivalent MC parameters were estimated 426 from non-linear failure envelopes of direct shear tests on scalped tunneling rock spoils. These tangential MC parameters have been used for the back-analysis of average measured pipejacking forces through highly fractured rock formations of varying geology. Values of $\sigma_{E V}$ were computed based on Eq. (2) to provide indication of the arching effect in the studied 430 drives. The back-analyzed $\mu_{\text {avg }}$ values have been compared against $\mu$ values recommended by 431 Stein et al. (1989) for lubricated drives. The $\mu_{\text {avg }}$ values showed that the pipe-jacking drives were lubricated, with the exception of Drive D which was affected by stoppages. These backanalyzed $\mu_{\text {avg }}$ values were verified by the volume of injected lubrication. The effects of arching, lubrication and stoppages shall be discussed hereinafter.

\section{DISCUSSION}

\section{Effect of arching on jacking forces}

In Drive A (sandstone), the calculated $\sigma_{E V}$ value of $-20.8 \mathrm{kN} / \mathrm{m}^{2}$ was much lower (representing relatively more arching effect) than that determined for Drive B (shale) at 34.1 $\mathrm{kN} / \mathrm{m}^{2}$, resulting in approximately two times lower jacking forces for Drive A. Jacking speeds were slightly higher in Drive A than in Drive B. In Drive A, the average injected 
fraction of the theoretical overcut volume of $12,180 \mathrm{~L}$ for $140 \mathrm{~m}$. This may have explained

443 the back-analyzed $\mu_{\text {avg }}$ of 0.31 , which is close to the 0.3 upper limit suggested for lubricated

444 drives by Stein et al. (1989).

445 The volume of lubricant injected for Drive B was $682 \mathrm{~L} / \mathrm{m}$, which was significantly in 446 excess of the theoretical overcut volume. The large volume of lubricant was injected as a 447 response to mitigate excessive increase in jacking forces. Back-analysis of the subsequent 448 jacking forces resulted in $\mu_{\text {avg }}$ of 0.20 , which corresponds with the margin of 0.1 to 0.3 recommended for well-lubricated pipe-jacking drives by Stein et al. (1989).

The effect of geology on jacking forces, and consequently on jacking speed and lubricant use was also apparent in Drive C (Test 3) through phyllite (see Fig. S6). The stress reduction at the pipe crown due to presence of arching $\left(\sigma_{E V}=-22.3 \mathrm{kN} / \mathrm{m} 2\right)$ could also be attributed to phyllite, which is characterized as being intensely folded with steep dips (Tan, 1993). Folds were also depicted in micrographs of phyllite (see Fig. S1(c)). These geological features created a structurally stable bore, allowing for re-distribution of soil stresses around the outer peripheral of the pipeline, i.e. arching.

The erratic structure of phyllite also reduced the lubrication injected, as the intense folding 458 likely reduced the permeation of lubricant into the surrounding geology. The retention of lubrication in the overcut ensured that the discretization of a lubricating layer was maintained. This phenomenon has allowed Drive $\mathrm{C}$ to record the highest observed jacking speeds across 461 the various drives studied. The reduction of stresses acting on the pipe outer surface together 462 with the retention of lubricant resulted in relatively low jacking forces. This resulted in an 463 average measured jacking force of only $4.8 \mathrm{kN} / \mathrm{m}$, for which the back-analyzed $\mu_{\text {avg }}$ was 0.07 , 464 significantly lower than the recommended value of 0.1 by Stein et al. (1989). 
well in excess of the theoretical overcut volume. It was likely that much of the injected lubrication was lost into the surrounding geology through fissures. However, Drive D encountered extended stoppage at the clay-shale interface, resulting in highly scattered jacking forces in the shale section (see Fig. 3(d)).

These observations indicate that geology had a significant effect on the jacking forces due to the stresses acting on the pipe by virtue of the arching effect. Subsequently, jacking forces affected the response of the construction process, i.e. lubricant usage and jacking speeds. This shows the coupling of arching and lubrication effects on jacking forces during pipe-jacking. Therefore, it is summarized that:

(i) Sandstone (Drive A): Significant arching, relatively low jacking forces; subsequently lower lubricant usage.

(ii) Phyllite (Drive C): Strongest arching due to folds and metamorphic nature, lowest jacking forces; subsequently moderate lubricant usage.

(iii)Shale (Drive B \& D): Reduced arching, relatively high jacking forces; subsequently higher lubricant usage.

\section{Effect of geology on lubrication}

Drive A in sandstone had minimal lubrication, with only $47 \mathrm{~L} / \mathrm{m}$ injected into the

484 theoretical overcut of $87 \mathrm{~L} / \mathrm{m}$ as summarized in Table 4 . However, the back-analyzed $\mu_{\text {avg }}$ of 4850.31 still corresponded well with the recommended upper limit of 0.3 as recommended by Stein et al. (1989) for lubricated drives. Drives B \& C seem to be well-lubricated, as the back-analyzed values of $\mu_{\text {avg }}$ were within the limits of 0.1 and 0.3 as recommended by Stein et al. (1989) for lubricated pipe-jacking drives. For Drive B, the volume of injected lubricant was $682 \mathrm{~L} / \mathrm{m}$, largely in excess of the theoretical overcut of $87 \mathrm{~L} / \mathrm{m}$ (see Table 4). For Drive $\mathrm{C}$, the volume of injected lubricant amounted to $181 \mathrm{~L} / \mathrm{m}$, compared to the theoretical overcut of $113 \mathrm{~L} / \mathrm{m}$. In both Drives B \& C, the injected lubrication was in excess of the theoretical 
overcut annulus, implying a continuous effort to saturate the overcut annulus. However, in

493 Drive B, it seems that there was significant loss of lubrication in order to sustain well-

494 lubricated conditions during pipe-jacking.

495 The excessive injection of lubricant observed in Drives B \& D indicated a loss of 496 lubrication during the pipe-jacking works. This could imply difficulties in maintaining a 497 watertight overcut, most likely due to surrounding rock fissures or the inability of the 498 lubrication to form a filter cake of low permeability (Pipe Jacking Association, 1995).

499 A permeable overcut would mitigate the establishment of a discrete lubricating layer 500 between the pipe and the surrounding geology. Fig. 5(a) shows a schematic illustration of the

501 postulated lubrication scenario for Drives B \& D. The lack of lubrication retained in the 502 overcut could also cause an increase in pipe-rock contact due to the loss of buoyant 503 lubricating forces acting on the pipe, that otherwise would have supported the pipe in fluid suspension (French Society for Trenchless Technology, 2006; Pipe Jacking Association, 1995). Fig. 5(b) shows how buoyant forces can be achieved in a stable watertight bore, which was the postulated situation for Drives A \& C.

\section{Effect of stoppages on jacking forces}

508 Stoppages also had significant effects on jacking forces during tunneling through rock. In

509 Drive D, the initial transition from clay into rock corresponded with low jacking speeds of 3 $510 \mathrm{~mm} / \mathrm{min}$ (see Fig. S7), indicating difficulties in traversing through the change in geology.

511 This difficulty was reflected by the suspension of tunneling activities lasting 19 days. Upon 512 resumption of tunneling works, the average volume of injected lubricant increased from 380

$513 \mathrm{~L} / \mathrm{m}$ in clay to $729 \mathrm{~L} / \mathrm{m}$ in rock, compared with a theoretical overcut volume of $113 \mathrm{~L} / \mathrm{m}$. For 514 the shale section, the average measured jacking force was $81.1 \mathrm{kN} / \mathrm{m}$, with a computed $\sigma_{E V}$ of $51511.7 \mathrm{kN} / \mathrm{m}^{2}$. The back-analyzed $\mu_{\text {avg }}$ of 0.71 easily exceeded the suggested values for 516 lubricated drives. It is also noted that the jacking forces in this shale section of Drive D 
517 fluctuated greatly. The line of best fit depicting the average measured jacking force was

518 accurate to only $R^{2}=0.45$. Restarting of jacking works after extended stoppages produce

519 large static frictional resistance (Chapman and Ichioka, 1999; Norris, 1992; Sofianos et al., 520 2004). The fluctuation of jacking forces seemed to have resulted from the restarting of works.

521 Additionally, stoppages can significantly impact lubricant use, particularly when pipe-jacking

522 through fissured geology. Any lubricant present in the overcut would be lost into fissures, 523 which act as drains. Upon resumption of pipe-jacking, the void overcut would need to be 524 refilled with lubricant. Re-injection of lubrication is usually ineffective during a restart due to 525 squeezing of the soil and rock surrounding the pipeline. Ground squeezing reduces the 526 overcut area and increases pipe-rock contact area. Full lubrication of the overcut is able to 527 provide uplift and buoyancy to the pipeline, allowing for full suspension of the jacked pipes. 528 This results in reduced contact between the pipe and the surrounding geology, particularly at 529 the pipe invert.

\section{CONCLUSIONS}

531 Tunneling rock spoils collected from the decantation chambers of four different pipejacking sites in Kuching City, Malaysia were tested for the assessment of physical characteristics and geotechnical strength properties. The scalped test specimens were

534 classified as sand-sized and poorly-graded. Direct shear tests were conducted on these

535 scalped, reconstituted tunneling rock spoils in order to characterize them so that assessment of pipe-jacking forces could be better understood and reliably estimated.

537 Results from the direct shear tests were then applied to a well-established jacking force model and subsequently benchmarked against field measured jacking loads. The assessment of jacking forces was conducted by considering the vertical stresses at the pipe crown, $\sigma_{E V}$ and the volumes of lubricant injected. The back-analyzed frictional coefficient values derived from the four pipe-jacking drives in the Tuang Formation of Kuching City have been found 
542 to be reliable and have been explained in relation to their surrounding geologies. The

543 consistencies in findings and discussions made herein are important for the reconstituted rock

544 spoils to be considered as friable, highly weathered 'soft rock', thus exhibiting characteristics

545 that tend towards soil behavior. This has allowed for assessment of pipe-jacking forces using

546 jacking force equations developed for pipe-jacking drives in soil. Water-tightness of the

547 overcut region has been found to be important in maintaining a discrete layer of lubrication

548 that can relieve frictional stresses along the pipe-rock interface. Comparison of the studied

549 drives has shown that arching effects, jacking forces, amount and pattern of lubricant use as

550 well as jacking speeds can be strongly related to the traversed geologies during pipe-jacking

551 works. Stoppages were observed to be a significant factor that can lead to higher jacking

552 forces upon resumption of a jacking drive. Although the assessment of jacking forces through

553 rocks is limited in existing jacking force models, the current study shows that back-analyzed

$554 \mu_{\text {avg }}$ can be used to evaluate pipe-jacking forces through weathered geology.

\section{ACKNOWLEDGMENT}

556 The Authors would like to express their thanks for the generosity shown by Hock Seng

557 Lee Bhd. and Jurutera Jasa (Sarawak) Sdn. Bhd. during this study. The authors are also

558 thankful to Ms. Hsiao-Yun Leong, Mr. Mohammud Irfaan Peerun, and Mr. Yi-Zhou Tan for

559 assisting in the work described in this paper.

\section{SUPPLEMENTAL DATA}

561 Figs. S1 to S10 are available online in the ASCE Library (www.ascelibrary.org).

\section{REFERENCES}

563 Anubhav, S., and Basudhar, P. K. (2013). "Interface behavior of woven geotextile with rounded and angular particle sand.” J. Mater. Civ. Eng., 25(12), 10.1061/(ASCE)MT.1943-5533.0000774. 
Anyaegbunam, A. J. (2015). "Nonlinear power-type failure laws for geomaterials: synthesis from triaxial data, properties, and applications." Int. J. Geomech., 15(1), 04014036.

Arulrajah, A., Rahman, M. A., Piratheepan, J., Bo, M. W., and Imteaz, M. (2013). "Evaluation of interface shear strength properties of geogrid-reinforced construction and demolition materials using a modified large scale direct shear testing apparatus.” J. Mater. Civ. Eng., 26(5), 10.1061/(ASCE)MT.1943-5533.0000897.

American Society for Testing and Materials (ASTM). (2000), Standard Practice for Classification of Soils for Engineering Purposes (Unified Soil Classification System), ASTM-D2487-00, West Conshohocken, PA.

American Society for Testing and Materials (ASTM). (2002), Standard Test Method for Particle-Size Analysis of Soils, ASTM-D422-63, West Conshohocken, PA.

American Society for Testing and Materials (ASTM). (2003), Standard Test Method for Direct Shear Test of Soils under Consolidated Drained Conditions, ASTM-D3080-03, West Conshohocken, PA.

578 Barla, M., Camusso, M., and Aiassa, S. (2006). "Analysis of jacking forces during microtunnelling in limestone.” Tunn. Undergr. Sp. Tech., 21(6), 668-83.

580 Bhasin, R., Barton, N., Grimstad, E., and Chryssanthakis, P. (1995). "Engineering geological characterization of low strength anisotropic rocks in the Himalayan region for assessment of tunnel support." Eng. Geol., 40(3-4), 169-93.

Cerato, A. B., and Lutenegger, A. J. (2006). "Specimen size and scale effects of direct shear box tests of sands." Geotech. Test. J., 29(6), 507-16.

Chapman, D. N., and Ichioka, Y. (1999). "Prediction of jacking forces for microtunnelling operations." Tunn. Undergr. Sp. Tech., 14(1), 31-41.

587 Charles, J. A., and Watts, K. S. (1980). "The influence of confining pressure on the shear strength of compacted rockfill." Géotechnique, 30(4), 353-67.

Choo, C. S., and Ong, D. E. L. (2012). "Back-analysis of frictional jacking forces based on shear box testing of excavated spoils." Proc., 2nd Int. Conf. on Geotechnique, Construction Materials and Environment, GEOMATE International Society, Tsu, Mie, Japan, pp. 462-7. 
592 Collins, I. F., Gunn, C. I. M., Pender, M. J., and Yan, W. (1988). "Slope stability analyses for

593 materials with a non-linear failure envelope.” Int. J. Numer. Anal. Meth. Geomech., 12(5), 533-50.

594 De Mello, V. F. B. (1977). "Reflections on design decisions of practical significance to embankment 595 dams." Géotechnique, 27(3), 281-354.

596 Deere, D. U. 1989, Rock quality designation (RQD) after twenty years, U.S. Army Corps of Engineers

597 Contract Report GL-89-1, Waterways Experiment Station, Vicksburg, Mississippi.

598 Desai, C. S., and Salami, M. R. (1987). "Constitutive model for rocks.” J. Geotech. Engrg., 113(5),

599 10.1061/(ASCE)0733-9410(1987)113:5(407).

600 Drescher, A., and Christopoulos, C. (1988). "Limit analysis slope stability with nonlinear yield

601 condition.” Int. J. Numer. Anal. Meth. Geomech., 12(3), 341-5.

602 French Society for Trenchless Technology (2006). Microtunneling and Horizontal Drilling :

603 Recommendations : French National Project "Microtunnels" : Recommendations, ISTE Ltd,

604 London.

605 Gurocak, Z., Solanki, P., Alemdag, S., and Zaman, M. M. (2012). "New considerations for empirical 606 estimation of tensile strength of rocks.” Eng. Geol., 145-1461-8.

607 Head, K. H. (1992). Manual of soil laboratory testing. Vol. 2, Permeability, shear strength and 608 compressibility tests, Halsted Press, New York.

609 Iai, M., and Luna, R. (2011). "Direct shear tests on JSC-1A lunar regolith simulant." J. Aerosp. Eng., $610 \quad 24(4), 10.1061 /($ ASCE)AS.1943-5525.0000082.

611 Jasinge, D., Ranjith, P. G., Choi, S. K., Kodikara, J., Arthur, M., and Li, H. (2009). "Mechanical 612 properties of reconstituted Australian black coal.” J. Geotech. Geoenviron. Eng., 135(7),

613 10.1061/(ASCE)GT.1943-5606.0000010.

614 Jewell, R. A. (1986). "Direct shear tests on sand.” Géotechnique, 39(2), 309-22.

615 Lade, P. V. (2010). “The mechanics of surficial failure in soil slopes.” Eng. Geol., 114(1-2), 57-64.

616 Lade, P. V., Yamamuro, J. A., and Bopp, P. A. (1996). "Significance of particle crushing in granular

617 materials.” J. Geotech. Engrg., 122(4), 10.1061/(ASCE)0733-9410(1996)122:4(309).

618 Li, Y. R., and Aydin, A. (2010). "Behavior of rounded granular materials in direct shear: Mechanisms 619 and quantification of fluctuations.” Eng. Geol., 115(1-2), 96-104. 
620 Norris, P. M. (1992). "The behaviour of jacked concrete pipes during site installation", PhD thesis,

621 Pembroke College, Oxford University, viewed 4 February 2010.

622 Ong, D. E. L., and Choo, C. S. (2011). "Sustainable construction of a bored pile foundation system in $623 \quad$ erratic phyllite." ASEAN Australian Engineering Congress.

624 Osumi, T. (2000). “Calculating jacking forces for pipe jacking methods.” No-Dig International $625 \quad$ Research, (October, 2000), 40-2.

626 Pellet-Beaucour, A. L., and Kastner, R. (2002). "Experimental and analytical study of friction forces 627 during microtunneling operations.” Tunn. Undergr. Sp. Tech., 17(1), 83-97.

628 Pellet, F. L., and Keshavarz, M. (2014). "Shear behavior of the interface between drilling equipments 629 and shale rocks." J Petrol Explor Prod Technol, 4(3), 245-54.

630 Pipe Jacking Association (1995). Guide to best practice for the installation of pipe jacks and 631 microtunnels, 1st edn, Pipe Jacking Association, London, England.

632 Potyondy, J. G. (1961). "Skin friction between various soils and construction materials." 633 Géotechnique, 11(4), 339-53.

634 Ramamurthy, T., Rao, G. V., and Singh, J. (1993). "Engineering behaviour of phyllites.” Eng. Geol., 635 33(3), 209-25.

636 Saroglou, H., Marinos, P., and Tsiambaos, G. (2004). "The anisotropic nature of selected 637 metamorphic rocks from Greece.” J. S. Afr. Inst. Min. Metall., 104(4), 217-22.

638 Shea Jr, W. T., and Kronenberg, A. K. (1993). "Strength and anisotropy of foliated rocks with varied mica contents.” J. Struct. Geol., 15(9-10), 1097-121.

640 Shou, K. J., Yen, J., and Liu, M. (2010). “On the frictional property of lubricants and its impact on 641 jacking force and soil-pipe interaction of pipe-jacking." Tunn. Undergr. Sp. Tech., 25(4), 469-77.

642 Simoni, A., and Houlsby, G. T. (2006). "The direct shear strength and dilatancy of sand-gravel 643 mixtures.” Geotech. Geol. Eng., 24(3), 523-49.

644 Singh, M., Rao, K. S., and Ramamurthy, T. (2002). "Strength and deformational behaviour of a $645 \quad$ jointed rock mass.” Rock Mech. Rock Eng., 35(1), 45-64.

646 Sofianos, A. I., Loukas, P., and Chantzakos, C. (2004). "Pipe jacking a sewer under Athens.” Tunn. 647 Undergr. Sp. Tech., 19(2), 193-203. 
648 Soon, S. C., and Drescher, A. (2007). "Nonlinear failure criterion and passive thrust on retaining 649 walls.” Int. J. Geomech., 7(4), 318-22.

650 Staheli, K. (2006). "Jacking force prediction an interface friction approach based on pipe surface 651 roughness”, PhD thesis, Georgia Institute of Technology, viewed 29 January 2010.

652 Standards Australia. (1993), Geotechnical site investigations, AS 1726-1993, Australia.

653 Standards Australia. (1998), Soil strength and consolidation tests - Determination of the shear strength 654 of a soil - Direct shear test using a shear box, AS 1289.6.2.2-1998, Australia.

655 Stein, D., Möllers, K., and Bielecki, R. (1989). Microtunnelling : Installation and Renewal of 656 Nonman-Size Supply and Sewage Lines by the Trenchless Construction Method, Ernst, Berlin, 657 Germany.

658 Tan, D. N. K. (1993). Geology of the Kuching Area, West Sarawak, Malaysia, Geological Survey of 659 Malaysia, Kuching, Malaysia.

660 Terzaghi, K. (1936). "Stress distribution in dry and in saturated sand above a yielding trap-door." 661 Proc., 1st Intl. Conf. on Soil Mechanics and Foundation Engineering, pp. 307-11.

662 Terzaghi, K. (1943). Theoretical soil mechanics, John Wiley \& Sons, Inc.

663 Tiwari, R. P., and Rao, K. S. (2007). "Response of an anisotropic rock mass under polyaxial stress 664 state.” J. Mater. Civ. Eng., 19(5), 10.1061/(ASCE)0899-1561(2007)19:5(393).

665 Wang, J. J., Zhang, H. P., Tang, S. C., and Liang, Y. (2013). “Effects of particle size distribution on 666 shear strength of accumulation soil.” J. Geotech. Geoenviron. Eng., 139(11), 667 10.1061/(ASCE)GT.1943-5606.0000931.

668 Yang, X. L., and Yin, J. H. (2004). “Slope stability analysis with nonlinear failure criterion.” J. Eng. $669 \quad$ Mech., 130(3), 10.1061/(ASCE)0733-9399(2004)130:3(267).

670 Yilmaz, I. (2009). “A new testing method for indirect determination of the unconfined compressive 671 strength of rocks.” Int. J. Rock Mech. Min., 46(8), 1349-57.

672 Yu, X., Ji, S., and Janoyan, K. D. (2006). "Direct shear testing of rockfill material." GeoShanghai 673 2006, American Society of Civil Engineers, Reston, Virginia, pp. 149-55. 
Table 1. Physical properties of scalped tunneling rock spoils.

\begin{tabular}{|c|c|c|c|c|}
\hline Test no. / Drive & Test 1 / Drive A & Test 2 / Drive B & Test 3 / Drive C & Test 4 / Drive D \\
\hline Geology & Sandstone & Shale & Phyllite & Shale \\
\hline$D_{60}(\mathrm{~mm})$ & 0.53 & 0.51 & 0.73 & 0.73 \\
\hline$D_{30}(\mathrm{~mm})$ & 0.25 & 0.35 & 0.29 & 0.27 \\
\hline$D_{10}(\mathrm{~mm})$ & 0.11 & 0.21 & 0.10 & 0.13 \\
\hline$D_{50}(\mathrm{~mm})$ & 0.45 & 0.45 & 0.55 & 0.61 \\
\hline $\begin{array}{l}\text { Weighted average } \\
\text { particle size, } D_{a v}(\mathrm{~mm})\end{array}$ & 1.02 & 0.59 & 0.80 & 0.82 \\
\hline Coefficient of uniformity, $C_{u}$ & 3.53 & 2.32 & 5.57 & 5.20 \\
\hline Coefficient of curvature, $C_{c}$ & 0.77 & 1.16 & 1.12 & 0.67 \\
\hline Material classification & $\begin{array}{l}\text { Poorly graded sand-sized } \\
\text { spoils (SP) }\end{array}$ & $\begin{array}{l}\text { Poorly graded sand-sized } \\
\text { spoils (SP) }\end{array}$ & $\begin{array}{l}\text { Poorly graded sand-sized } \\
\text { spoils (SP) }\end{array}$ & $\begin{array}{l}\text { Poorly graded sand-sized } \\
\text { spoils (SP) }\end{array}$ \\
\hline $\begin{array}{l}\text { Applied effective normal } \\
\text { stresses for direct shear tests } \\
(\mathrm{kPa})\end{array}$ & $25,50,75,100255,600$ & $50,100,250,400$ & $100,250,380,400$ & $150,375,395,500$ \\
\hline $\begin{array}{l}\text { Densities of tested samples } \\
\left(\mathrm{kN} / \mathrm{m}^{3}\right)\end{array}$ & $15.9-16.9$ & $13.7-14.8$ & $-{ }^{\mathrm{a}}$ & $15.5-16.7$ \\
\hline
\end{tabular}

${ }^{\mathrm{a}}$ Note: Measurements were not made for Test 3 specimens. 
Table 2. Shear strength of tunneling rock spoils and rockfill materials using power law functions, where $\tau=A \cdot\left(\sigma^{\prime}\right)^{B}$

\begin{tabular}{|c|c|c|c|c|}
\hline Material type & Geology & $A$ & $B$ & Source \\
\hline \multirow{6}{*}{$\begin{array}{l}\text { Tunneling rock } \\
\text { spoils }\end{array}$} & Sandstone (Test 1 - peak) & 4.68 & 0.76 & This study \\
\hline & Sandstone (Test 1 - residual) & 2.24 & 0.84 & \\
\hline & Phyllite (Test 3 - peak) & 1.92 & 0.87 & \\
\hline & Phyllite (Test 3 - residual) & 1.07 & 0.96 & \\
\hline & Shale (Test 4 - peak) & 3.86 & 0.79 & \\
\hline & Shale (Test 4 - residual) & 3.37 & 0.78 & \\
\hline \multirow[t]{9}{*}{ Rockfill } & Sandstone & 6.8 & 0.67 & Charles and \\
\hline & Slate & 5.3 & 0.75 & Watts (1980) \\
\hline & Slate & 3.0 & 0.77 & \\
\hline & Basalt & 4.4 & 0.81 & \\
\hline & Basalt & 1.54 & 0.821 & De Mello (1977) \\
\hline & Diorite & 1.10 & 0.870 & \\
\hline & Conglomerate & 1.27 & 0.846 & \\
\hline & Conglomerate & 1.19 & 0.881 & \\
\hline & Conglomerate & 1.59 & 0.808 & \\
\hline
\end{tabular}


Table 3. Parameters used in pipe-jacking force model for back-analyses of $\mu_{\text {avg }}$

\begin{tabular}{|c|c|c|c|c|c|}
\hline \multicolumn{2}{|l|}{ Drive (Test no.) } & Drive A (Test 1) & Drive B (Test 2) & Drive C (Test 3) & Drive D (Test 4) \\
\hline \multicolumn{2}{|l|}{ Geology } & Sandstone & Shale & Phyllite & Shale \\
\hline \multirow{3}{*}{\multicolumn{2}{|c|}{$\begin{array}{l}D_{e}(\mathrm{~m}) \\
\gamma\left(\mathrm{kN} / \mathrm{m}^{3}\right) \\
h(\mathrm{~m})\end{array}$}} & 1.43 & 1.43 & 1.78 & 1.78 \\
\hline & & 22 & 22 & 22 & 22 \\
\hline & & 12.5 & 12.5 & 18.5 & 19.5 \\
\hline $\begin{array}{l}\text { Power function, } \\
\tau=A \cdot\left(\sigma^{\prime}\right)^{B} \text { applied to } \\
\text { data points }^{\mathrm{a}}\end{array}$ & $\begin{array}{l}A_{p} \\
B_{p} \\
A_{r} \\
B_{r} \\
\end{array}$ & $\begin{array}{l}4.68 \\
0.76 \\
2.24 \\
0.84 \\
\end{array}$ & $\begin{array}{l}\text { N/A since power } \\
\text { function is not } \\
\text { applicable. }\end{array}$ & $\begin{array}{l}3.86 \\
0.79 \\
3.37 \\
0.78 \\
\end{array}$ & $\begin{array}{l}1.92 \\
0.87 \\
1.07 \\
0.96\end{array}$ \\
\hline MC parameters ${ }^{\mathrm{a}}$ & $\begin{array}{l}c_{p}^{\prime}(\mathrm{kPa}) \\
\phi^{\prime}{ }_{p}\left({ }^{\circ}\right) \\
c^{\prime}{ }_{r}(\mathrm{kPa}) \\
\phi^{\prime}{ }_{r}\left({ }^{\circ}\right)\end{array}$ & $\begin{array}{l}50.8 \\
47.8 \\
24.2 \\
39.6\end{array}$ & $\begin{array}{c}0 \\
41.4 \\
0 \\
37.6\end{array}$ & $\begin{array}{l}57.8 \\
44.3 \\
50.3 \\
39.2\end{array}$ & $\begin{array}{c}29.0 \\
38.7 \\
8.3 \\
39.4\end{array}$ \\
\hline \multicolumn{2}{|l|}{$\begin{array}{l}\text { Average measured } \\
\text { jacking forces }(\mathrm{kN} / \mathrm{m})\end{array}$} & 14.4 & 29.0 & 4.8 & 81.1 \\
\hline \multirow{2}{*}{\multicolumn{2}{|c|}{$\begin{array}{l}\text { Back-analyzed } \mu_{\text {avg }} \\
\text { using Eq. (1) } \\
R^{2}\end{array}$}} & 0.31 & 0.20 & 0.07 & 0.71 \\
\hline & & 0.93 & 0.90 & 0.78 & 0.45 \\
\hline
\end{tabular}

${ }^{a}$ Note: Subscript $p$ denotes peak values; subscript $r$ denotes residual values

${ }^{b}$ Note: Data points can be conveniently represented by line of best fit, hence power law is not necessary here. 
Table 4. Comparison of pipe-jacking performance for various drives

\begin{tabular}{|c|c|c|c|c|}
\hline $\begin{array}{l}\text { Test no. } \\
\text { Drive } \\
\text { Geology }\end{array}$ & $\begin{array}{c}1 \\
\text { Drive A } \\
\text { Sandstone }\end{array}$ & $\begin{array}{c}2 \\
\text { Drive B } \\
\text { Shale }\end{array}$ & $\begin{array}{c}3 \\
\text { Drive C } \\
\text { Phyllite }\end{array}$ & $\begin{array}{c}4 \\
\text { Drive D } \\
\text { Shale }\end{array}$ \\
\hline $\begin{array}{l}\text { Length of nearby rock cores extracted } \\
\text { (m) }\end{array}$ & 4.5 & 5.1 & 15.1 & 6.0 \\
\hline Average RQD $(\%)$ & 0 & 26.0 & 17.5 & 14.0 \\
\hline $\begin{array}{l}\text { Length of rock cores with } \mathrm{RQD}=0 \\
(\mathrm{~m})\end{array}$ & 4.5 & 0.65 & 7.6 & 0.7 \\
\hline $\begin{array}{l}\text { Average volume of lubricant injected } \\
\text { including losses }(\mathrm{L} / \mathrm{m})\end{array}$ & 47 & 682 & 181 & 729 \\
\hline $\begin{array}{l}\text { Average theoretical overcut volume } \\
(\mathrm{L} / \mathrm{m})\end{array}$ & 87 & 87 & 113 & 113 \\
\hline $\begin{array}{l}\text { Effective overburden pressure } \\
\text { (without arching) }\left(\mathrm{kN} / \mathrm{m}^{2}\right)\end{array}$ & 150 & 150 & 222 & 234 \\
\hline Average jacking speed (mm/min) & 16 & 10 & 44 & 34 \\
\hline $\begin{array}{l}\text { Average measured face support } \\
\text { pressure }\left(\mathrm{kN} / \mathrm{m}^{2}\right)\end{array}$ & 104 & 68 & 47 & 115 \\
\hline Cutter face diameter $(\mathrm{m})$ & 1.47 & 1.47 & 1.82 & 1.82 \\
\hline TBM weight (tonnes) & 15 & 15 & 20 & 20 \\
\hline Pipe weight $(\mathrm{kN} / \mathrm{m})$ & 17.3 & 17.3 & 11.6 & 11.6 \\
\hline Calculated $\sigma_{E V}\left(\mathrm{kN} / \mathrm{m}^{2}\right)($ Eq. (2)) & $-20.8^{\mathrm{a}}$ & 34.1 & $-22.3^{\mathrm{a}}$ & 11.7 \\
\hline $\begin{array}{l}\text { Average measured jacking forces } \\
(\mathrm{kN} / \mathrm{m})\end{array}$ & 14.4 & 29.0 & 4.8 & 81.1 \\
\hline Back-analyzed $\mu_{\text {avg }}$ & 0.31 & 0.20 & 0.07 & 0.71 \\
\hline
\end{tabular}

${ }^{a}$ Note: Negative values of $\sigma_{E V}$ (Eq. (2)) indicate possible presence of significant arching. For back-analysis of $\mu_{\text {avg }}$, these negative values of $\sigma_{E V}$ were adjusted to be equal to zero (Terzaghi, 1943). 

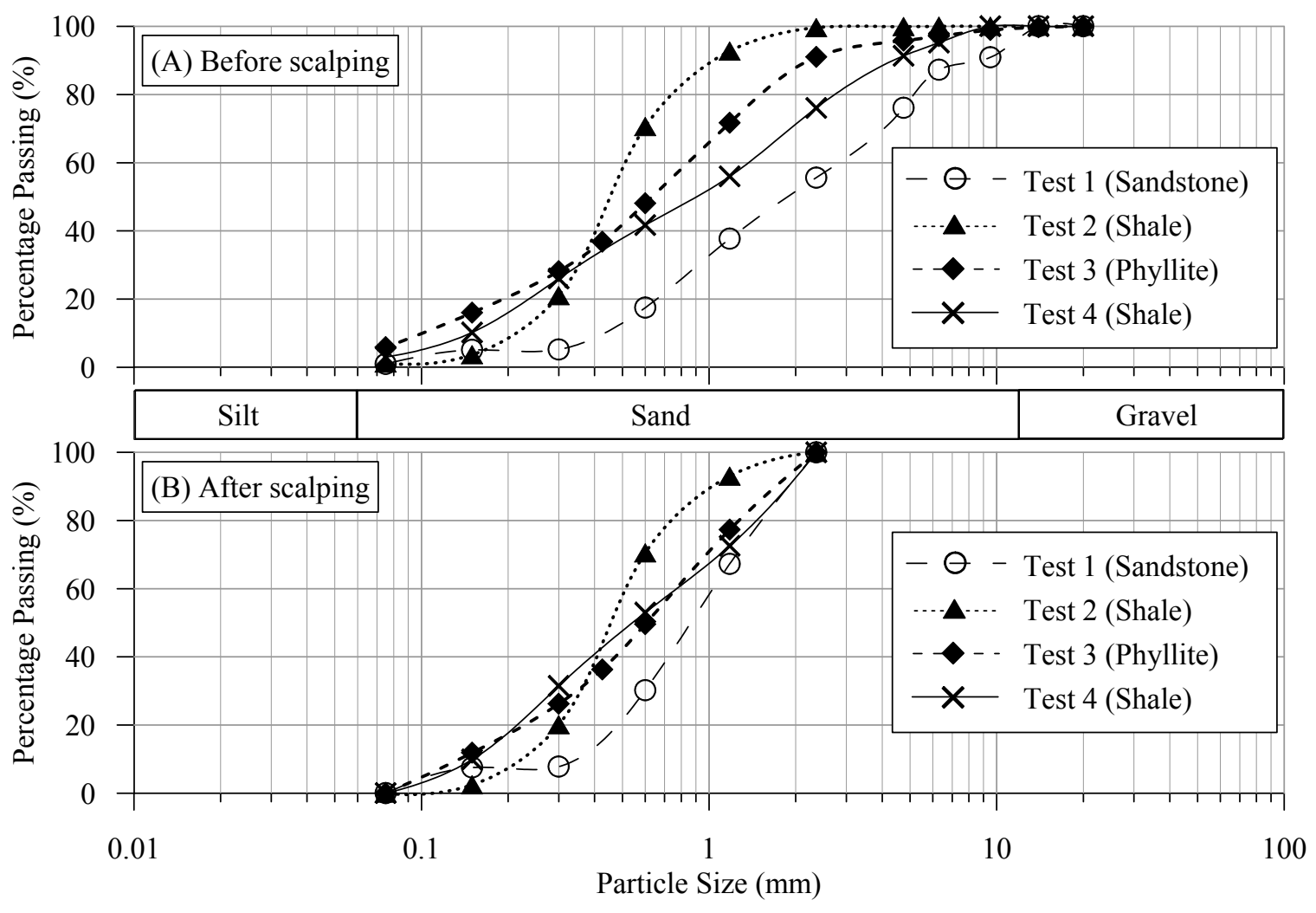

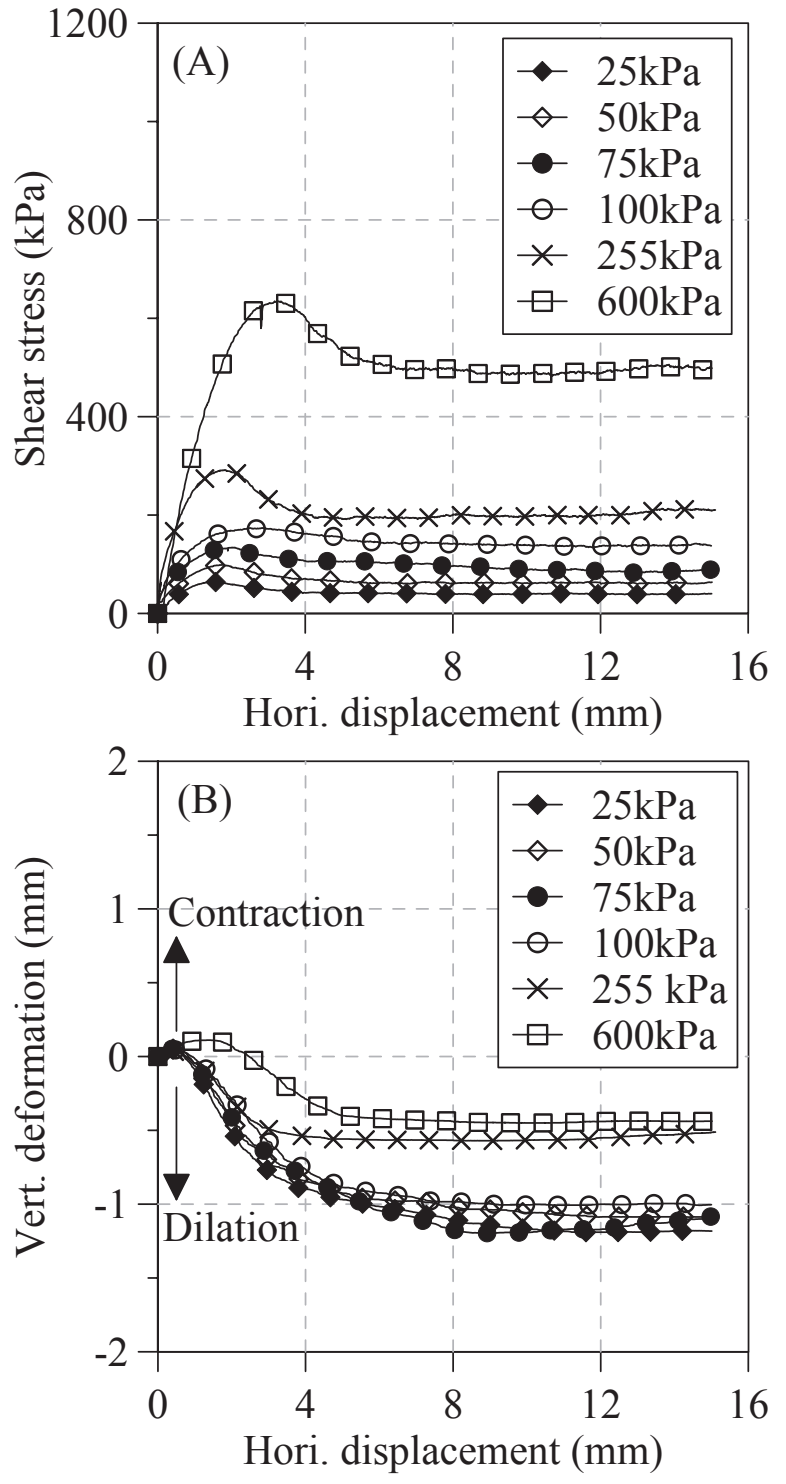

Hori. displacement (mm)

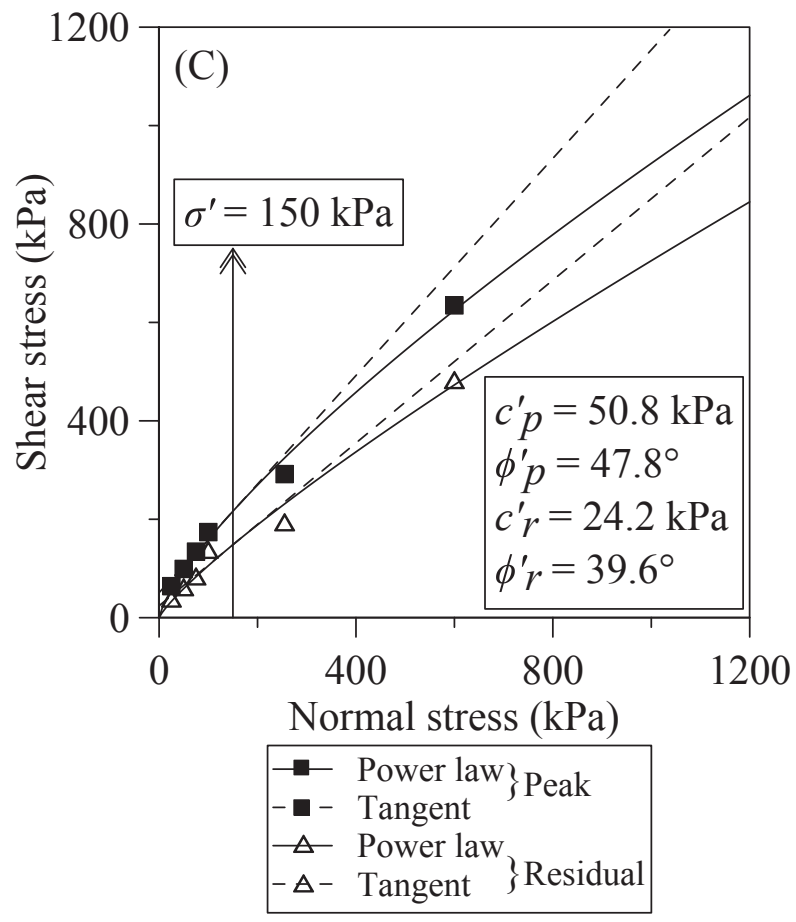

Graph titles:

(A) Shear stress vs horizontal displacement

(B) Vertical deformation vs horizontal deformation

(C) Interpretation of Mohr-Coulomb parameters 


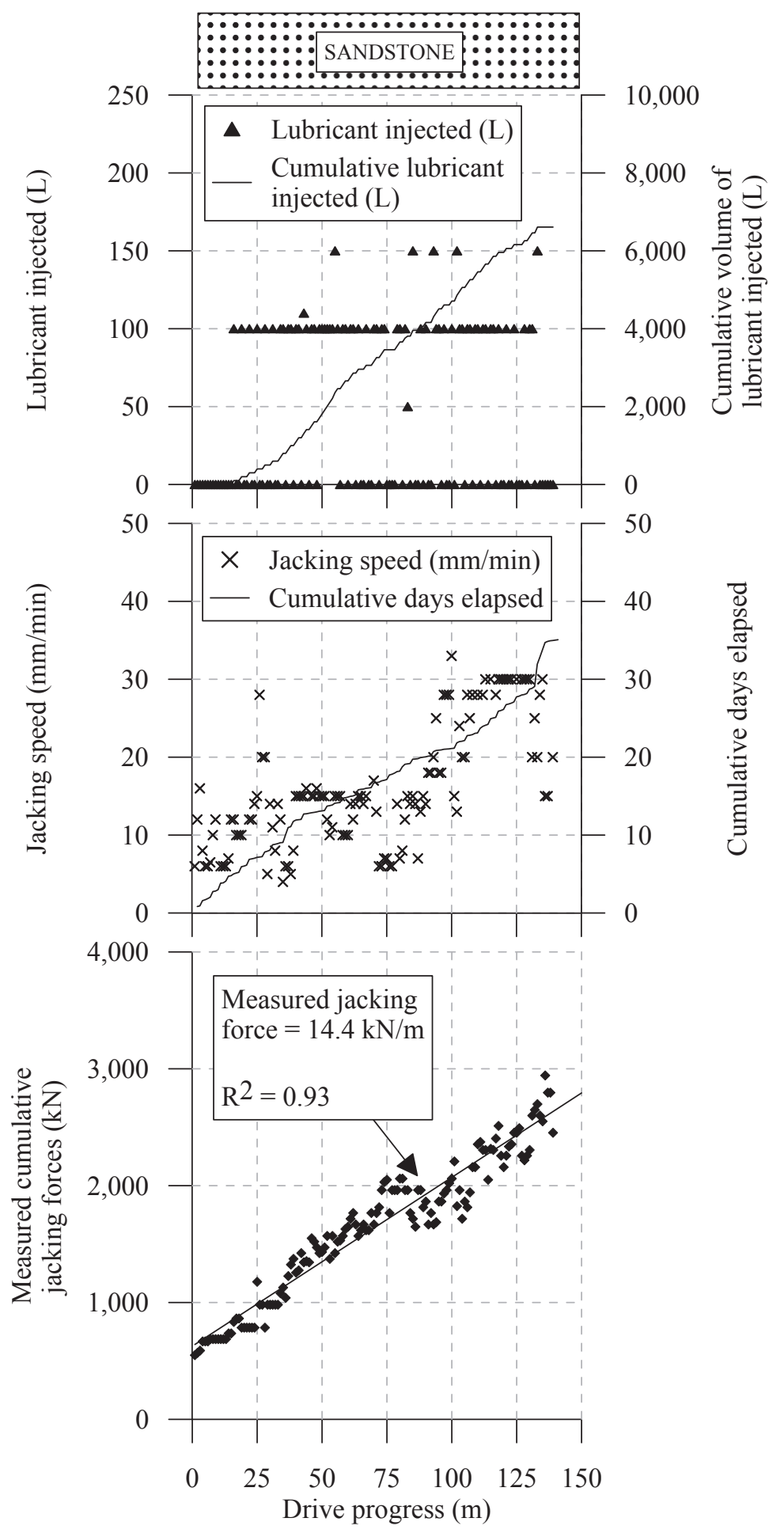




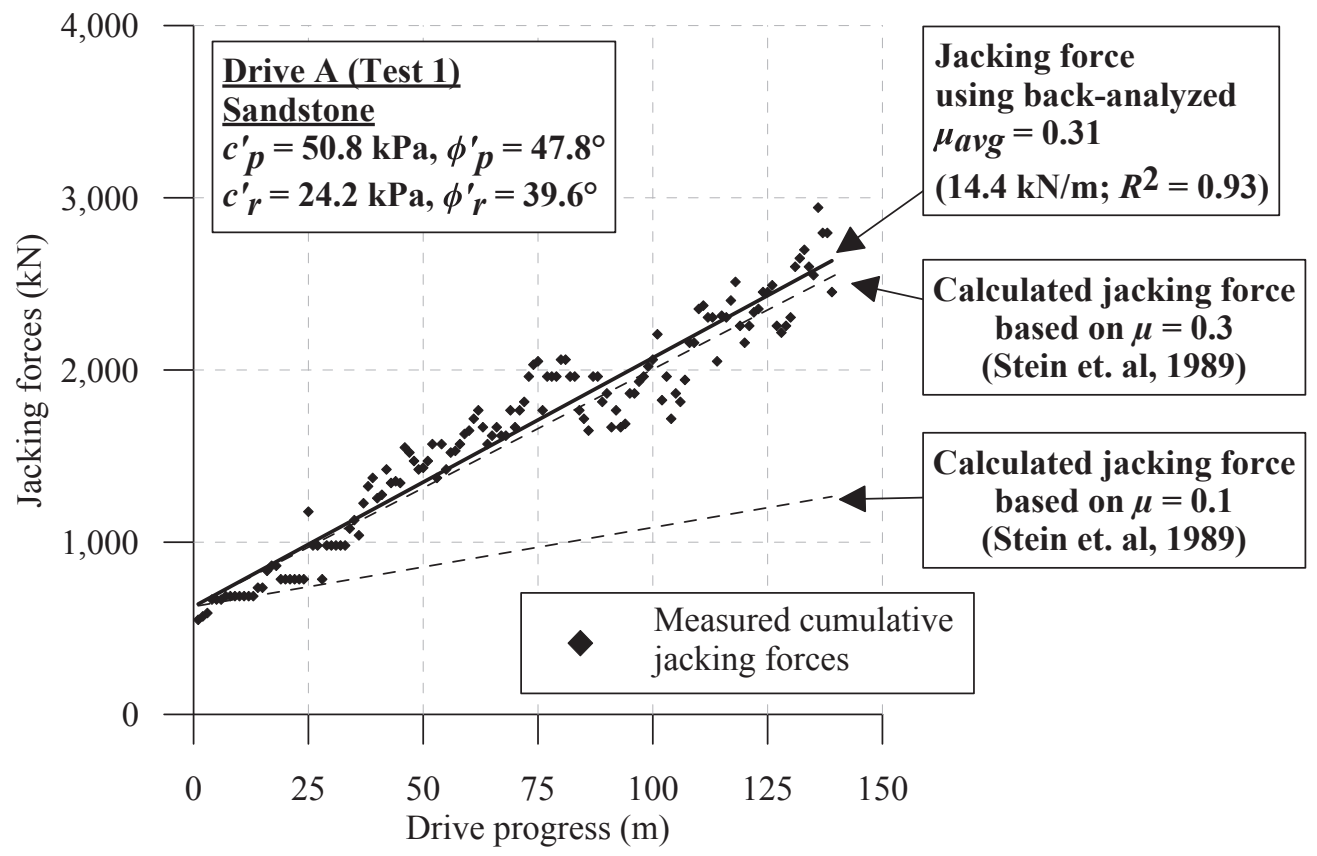

:::::::::::::::::::::::::::::::::::

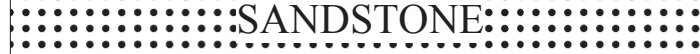



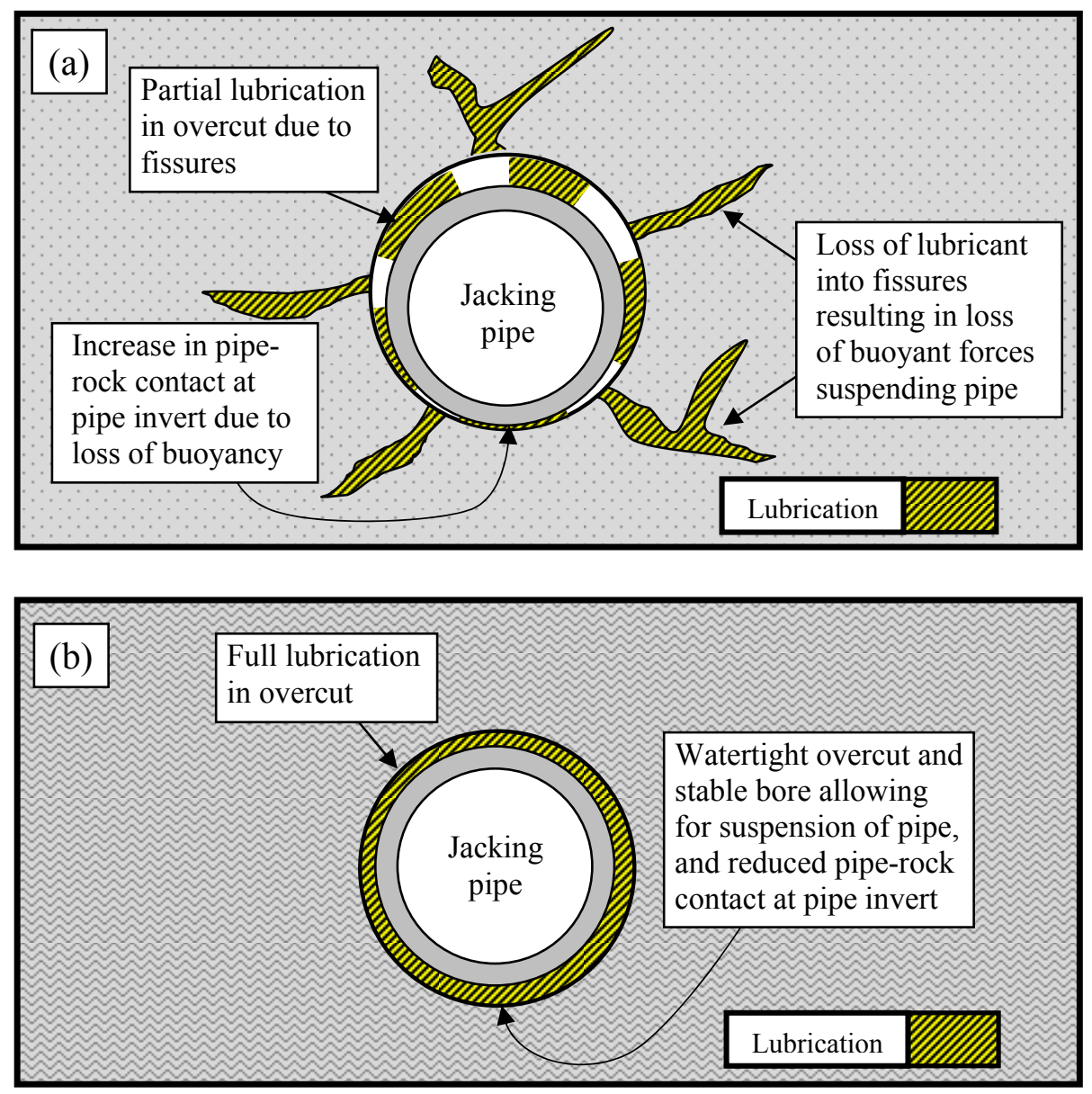


\section{LIST OF TABLES}

Table 1. Physical properties of scalped tunneling rock spoils.

Table 2. Shear strength of tunneling rock spoils and rockfill materials using power law functions, where

Table 3. Parameters used in pipe-jacking force model for back-analyses of $\mu_{\text {avg }}$

Table 4. Comparison of pipe-jacking performance for various drives 


\section{LIST OF FIGURES}

Fig. 1. Particle size distribution of tunneling rock spoils; (A) before scalping; (B) after scalping to create a direct shear specimen

Fig. 2. Results from direct shear testing of scalped tunneling rock spoils (Test 1)

Fig. 3. Variations in measured jacking forces, jacking speed and volume of injected lubricant for the studied drives (Drive A)

Fig. 4. Drive A (sandstone): Outcome of back-analyzed $\mu_{\text {avg }}$ in comparison to recommended upper \& lower bounds

Fig. 5. Schematic diagrams showing pipe behavior under different degrees of lubricant retention in tunnel overcut in varying geological conditions; (a) partial loss of lubricant into rock fissures; (b) minimal loss of lubricant in a 'watertight' rock mass 